\title{
Between absence and presence: Augmented Reality as a self-fiction poetic
}

\author{
Keywords \\ Photography, Augmented Reality, Poetic, Self-fiction, Cybrid.
}

This text comprises an excerpt of the Doctoral research completed in 2021, developed in the Line of Poetics and Processes of Performance in Arts (PPGARTES-UFPA), which will present a conceptual reflection about the creative process that unfolded poetically from the appropriation of an old family photo album. The album in question began to be observed as a place of overlapping time and space, triggering an internal movement of belonging by presenting itself as a place of poetic power due to the physical evidence that emerged from it. Through Augmented Reality, the empty spaces left by the time were occupied, following the tracks and telling another narrative through visual, textual, and sound layers, thus reconfiguring the album, which expanded and became a living space of memory activated by the cybrid experience. The way of facing the presence of absence and at the same time the absence of presence provoked me an inner movement of wanting more and more to belong to that space. There were countless times I approached this album and I was always worried about its gaps and emptiness in its narrative. And, by a sudden feeling of belonging to that space, I began to fill its "silence" and become part of that place. I have been calling this act the movement of self-fiction poetic. This concept is widely discussed in the book Essays on self-fiction, organized by Jovita Maria Gerheim and crossed my research, which I appropriated and used as an operative concept, thus comprising a movement that took place through the appropriation of an object, intervening in a poetic way, from which I became a character manifesting myself subjectively in the fictional narrative. Therefore, I articulated myself between the photographic language and other operational resources that mobile devices made possible, to recreate the space in mixtures with the past and the contemporary in a movement of mixing memories. The album presented itself as a space deconstructed by the action of time and subjects and through the poetic movement, I triggered a series of events, overlapping different times and spaces by inserting photographic files, video, text, and sound that activated this place as a living organism, revealing a new experience with memory. The reconfiguration process of this space was triggered exclusively by digital means. The idea of the movement of self-fiction poetic arose precisely because I brought photographic productions of my own in a mix with the photographs already present in the album. This intersection of authorship that unfolded in the presentation of another narrative, which includes me sometimes as a present character, sometimes as a hidden agent, allowed me to travel through the chain of memory and feel myself belonging to that space-time. By wanting to penetrate a past that was not mine, triggering subjective layers of information produced in the interstice of reality and fiction that photography allowed me, I was able to perceive the album beyond a memory space, but as a place of experience that opened and was available for interventions. 